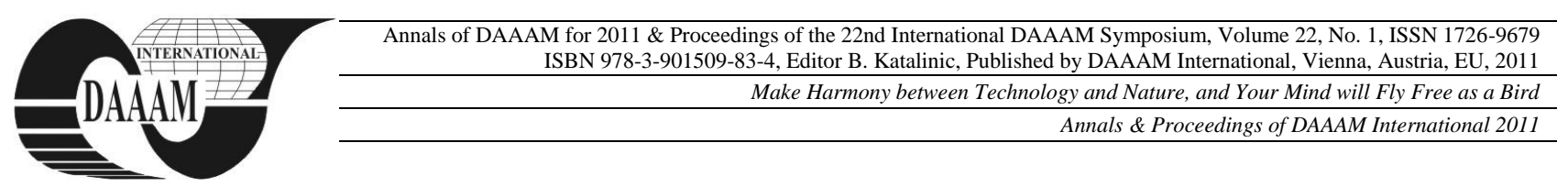

\title{
XAAS SERVICES AS MODERN INFRASTRUCTURE OF ITS
}

\author{
PERAKOVIC, D[ragan]; KULJANIC, T[ibor] - M[ijo] \& MUSA, M[ario]
}

\begin{abstract}
The paper gives an overview of the impact of significant changes within the ICT sector and the ability to deploy new services in intelligent transport systems (ITS). The emphasis of research on the analysis of features of new innovative services Traffic Information System Provider (TISP) in Croatia, based on XaaS paradigm, the function of implementing the necessary e-communications infrastructure and services of ITS.
\end{abstract}

Key words: TISP, ITS, traffic system, real-time information

\section{INTRODUCTION}

When speaking of the traffic system one has to identify two levels of traffic influence on the quality of living and the total economic development of a country. The traffic affects directly the lives of people, on the one hand regarding the individual mobility and accessibility of narrow and wider areas, and on the other hand regarding the rational usage of time and in the most general sense the quality of living. The traffic system is expected to facilitate faster, safer, more reliable, more comfortable and less expensive movement with enabled maximal personal mobility. One of the necessary preconditions to realise these expectations is the real-time information of all the participants in the traffic process with all the relevant data. Consequently, one should design and construct a traffic system that will implement advanced information-communication technology (ICT) in order to provide the backbone that will integrate the users' services based on the principles of intelligent transport systems (ITS), so that the system users could be provided with reliable, precise and timely information necessary for efficient realisation of the traffic process. In Republic of Croatia, is necessary to establish the model of the traffic information management system, that has not been done yet. The negative characteristics of the current information systems of traffic system users which at the moment fail to satisfy sufficiently the users' requirements have to be studied. The problem escalates by the arrival of numerous foreign motorised tourists who learned to use the information services of individual traffic information providers in their own country.

\section{USERS OF ITS SERVICES}

The introduction of new services into the communication systems has expanded the availability of information also to the mobile traffic participants. For planning the journey / transport the traffic participants need reliable, accurate and timely information about the status of the traffic system. The number of providers of such information and the technology of exchange, publication or delivery of information significantly influence the level of information of the traffic participants. The increase in the reliability and quality of information regarding the conditions in traffic is achieved by forming the users' ITS services, in order to allow precise, reliable, safe and fast delivery and exchange of information among the traffic system users in a timely and economically justified way.
The potential users of ITS information services include:

- Those who want ITS systems that will solve (or reduce) traffic problems, or supply passenger public information services, municipal authorities, public institutions, police, etc.,

- Those who build ITS systems, such as: system integrators, transport means manufacturers, telecom operators, providers of other information services, etc.

- Those who use ITS systems as primary and secondary users. Primary users benefit from useful information generated by the ITS operation, e.g. commuters, business users, users for the purposes of entertainment, travelling salesmen, passengers with disabilities, etc. Secondary users control the ITS system and provide input data in ITS. Examples of secondary users are the categories of traffic controllers, emergency services, etc.

\section{INFORMATION - COMMUNICATION INFRASTRUCTURE OF ITS SYSTEM}

Realization wide spectrum of services in ITS mean implementation of modern computers, senzors and communication systems. Therefore is especeally important telecommunication infrastructure which is responsible for ensurance of maximum distributed backbone for interconnection of terminal equipment, signaling and sensor equipment in buildings, controll and information spots, as well as mobile terminals in vechicles and users in movement.

The basic requirements for information-communication subsystem of ITS should meet the following demands:

- Enable transmission of various types of communication messages such as voice, data, images, video signal and telemetry signals,

- Ensure the use of different types of terminals (stationary, portable and mounted in vehicles),

- Provide communication between central office and regional offices i.e teams on the ground,

- Secure communication with services that are of special interest such as police, emergency medical service, fire department etc.,

- Ensure transfer of information from sensors that are placed on roads towards central office,

- Enable control of equipment for diverting traffic, which is located along roads, in the case of traffic jams,

- Provide an effective and economically justified use of radiofrequency spectrum,

- Provide high quality services and protection of confidential information.

Presentation of a generalised model of ITS with respect to the user and information communication connection between the participants in the transport system, is shown in the following figure. 


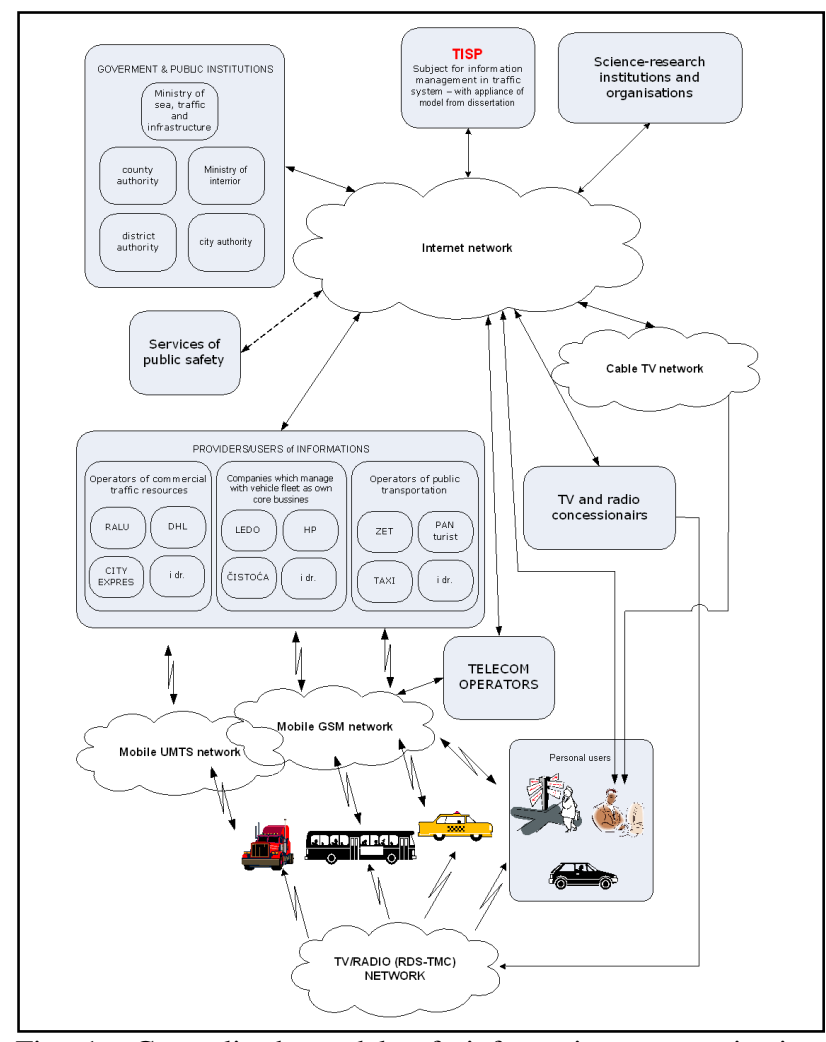

Fig 1. Generalised model of information-communication connection of traffic system users.

In figure 1. we have given an overview of the ITS model in which one can see the possibility of using the following communication technologies:

- Stationary or fixed communication which link fixed terminals,

- Mobile or wireless wide band communications, linking fixed and mobile (cellular) terminals,

- Purposeful, narrow band wireless (mobile) communications, connecting fixed (eg. toll and monitoring sites) and mobile terminals in vehicles,

- Wireless (mobile) communicaton between vehicles.

\section{ADVANCED XaAS SERVICES APPLICABLE AS INFRASTRUCTURE OF ITS}

The traditional supply chain of the telecom sector has been drastically redesigned, particularly by the introduction of an entire series of activities. Telecommunication operators are growing into Internet and computer service providers (ICSPs) and now, new services may be offered that directly contribute to the improvement of traffic system quality.

In their operation the telecom operators have to undertake a transformation in their business model in order to achieve four main goals:

- Increase of productivity due to high operational costs, insufficient process automation, inadequate management of business processes, inadequate systems,

- Increase of innovativeness due to the long period of introducing new services of inflexible and non-functional business processes of fragmented sector organisation and

- Increase in the agility because of the long time from order to service realisation.

All this as a consequence results in the provision of a wide range of services and solutions for all the users' segments. Particularly highlighted are the XaaS-based services that do not require capital investments, which the users of the government budget certainly find more interesting. Therefore, it is necessary to redesign the budget in order to reduce the budget expenditures for capital ICT investments and to start using XaaS solutions. Furthermore, XaaS solutions ensure access to data from anywhere, they are reliable regarding protection against data loss, and they allow faster and more efficient control of computers and applications. Different XaaS models are shown in figure 2.

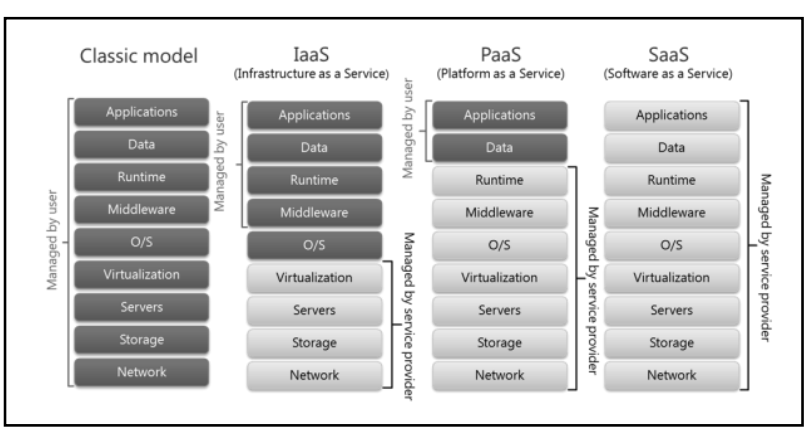

Fig 2. XaaS models

\section{CONCLUSION}

The research has shown that XaaS is a very suitable platform, both for private companies and corporations, and for the government. The advantages such as reliability, conditional security, high availability, low maintenance level (depending on the model) and scalability, are extremely interesting characteristics of XaaS platforms. However, attention should be paid to the problems of security and privacy of data and to the SLA agreement conditions. Regarding the delicate nature of data handled by ITS, additional efforts should be invested in defining the Service Layer Agreement (SLA), End User Licence Agreement (EULA) and Terms of Service (TOS) with special reference to data security and privacy. This method of negotiating services (by defining SLA, EULA and TOS) can only be observed by ICSPs so that in this case they are ideal partner for the provision of TISP XaaS platform. Modern mobile communication systems offer services which allow realizing of real-time informing of all the traffic system users, with the possibility of realizing financial profit of the TISP. Different business models of operation TISP will attract a large number of those interested in performing this, until now in the Republic of Croatia unrecognized activity.

\section{REFERENCES}

Nisbet, B. (2011) Monetizing the Cloud: XaaS Opportunities for Service Providers, IDC, Bethesda, USA

Jelušić, N.; Mrvelj, Š.; Matulin, M. (2010). Data Collection Method Analysis for Evaluation of Public Transport System Performances, Proceedings of the $17^{\text {th }}$ ITS World Congress, 25.-29.10.2010., Busan, South Korea

Peraković, D.; Remenar, V. \& Husnjak, S. (2011). Reminder based on the user's location, Proceedings of the $14^{\text {th }}$ International Conference on Transport Science ICTS 2011, 27 May 2011., Portorož, Slovenia, ISBN 978-961-6044-929, Zanne, M. \& Bajec, P. (Ed.), pp. 1-9, Fakulteta za pomorstvo in promet, Portorož, Slovenia

Peraković, D., Kuljanić, M.T. \& Šipek, K. (2011). Research issues of governance, risk management and compliance in information and communication infrastructure of ITS, Proceedings of the $19^{\text {th }}$ International Symposium on Electronics in Traffic ISEP 2011, 28 March 2011., Ljubljana, Slovenia, ISBN 978-961-6187-49-7, Anžek, M. \&etc. (Ed), P10., EZS, Ljubljana, Slovenia

*** (2011) http://www.tmforum.org - TM Forum, Accessed on: 2011-07-25

*** (2011) http://www.t-com.hr/poslovni/ict/tcloud/index.asp - Hrvatski telekom d.d., Accessed on: 2011-08-01 